\title{
EXAFS investigation of the destabilization of the Mg-Ni-Ti (H) system
}

Int. J. Hydrogen Energy 37 (2012) 5, 4161-4169, doi:10.1016/j.ijhydene.2011.11.107

Q. Zheng ${ }^{\mathrm{a}, \mathrm{b}}$, Y. Pivak ${ }^{\mathrm{a}}$, L. P. A. Mooij ${ }^{\mathrm{a}}$, A. M. J. van der Eerden ${ }^{\mathrm{b}}$, H. Schreuders ${ }^{\mathrm{a}}$, P. E. de Jongh ${ }^{\mathrm{b}}$, J. H. Bitter ${ }^{\mathrm{b}}$, B. Dam ${ }^{\mathrm{a}}$

${ }^{a}$ MECS, Department of Chemical Engineering, Delft Technology of University, Julianalaan 136, 2628 BL Delft, The Netherlands

${ }^{b}$ Inorganic Chemistry and Catalysis, Debye Institute for NanoMaterials Science, Utrecht University, Universiteitweg 99, 3584 CG Utrecht, The Netherlands

\section{Abstract}

Ti doping destabilizes the $\mathrm{Mg}_{2} \mathrm{NiH}_{4}$ system, reducing the hydrogenation enthalpy from - $64 \mathrm{~kJ} /\left(\mathrm{mol} \mathrm{H}_{2}\right)$ to around $-40 \mathrm{~kJ} /\left(\mathrm{mol} \mathrm{H}_{2}\right)$. However, the equilibrium pressure is hardly affected, as also the entropy of reaction changes. To understand this thermodynamic behavior it is essential to understand the structure of the phases present in the Ti doped $\mathrm{Mg}_{2} \mathrm{Ni}$ system in metallic and hydrogenated state. We used Extended X-ray Absorption Fine Structure (EXAFS) to investigate the local coordination of $\mathrm{Ni}$ and $\mathrm{Ti}$ atoms in $\mathrm{Mg}-\mathrm{Ni}-\mathrm{Ti}$ thin films both in the as-prepared as-well as in the hydrogenated state. In the as-prepared state two phases, $\mathrm{Mg}_{2} \mathrm{Ni}$ and TiNi or $\mathrm{TiNi}_{3}$, are formed, which transform in a single Ti-doped $\mathrm{Mg}_{2} \mathrm{NiH}_{4}$ phase in the hydrogenated state. These results are consistent with previous DFT calculations for this system.

PACS: 61.05.cj; 88.30.R-; 79.60.Dp; 61.46.-w; 64.60.My

Keyword: EXAFS; Hydrogen storage; Magnesium based; Doping; Thin films 


\section{INTRODUCTION}

Light (complex) metal hydrides are attractive candidates for the storage of hydrogen for mobile applications due to their reversibility and high volumetric and gravimetric storage densities [1]. Unfortunately, at the moment, no materials are available which combine high storage densities with suitable hydrogen adsorption/desorption properties at low temperatures $(\sim 473 \mathrm{~K})$, which is needed for their use in combination with a PEM fuel cell. For example $\mathrm{MgH}_{2}$ has a gravimetric hydrogen density of $7.7 \mathrm{wt} \%$. However, the enthalpy of hydrogenation is $\Delta H=-74 \mathrm{~kJ}$ $(\mathrm{mol} \mathrm{H})^{-1}$ which means that a temperature as high as $570 \mathrm{~K}$ is needed to release the hydrogen at atmospheric pressure [2]. Furthermore, the diffusion of hydrogen in the $\mathrm{MgH}_{2}$ phase is very slow and, unless high temperatures are used, a hydride blocking layer forms that prevents further hydrogenation of $\mathrm{Mg}$ [3]. Several studies report attempts to destabilize $\mathrm{MgH}_{2}$ by alloying Mg with transition metals (TM) elements such as $\mathrm{Ti}, \mathrm{V}, \mathrm{Mn}, \mathrm{Fe}, \mathrm{Ni}, \mathrm{Co}, \mathrm{Al}, \mathrm{Cu}$, and $\mathrm{Nb}$ [4-8]. The most extensively studied Mg-TM composite is $\mathrm{Mg}_{2} \mathrm{NiH}_{4}$, which stores $3.6 \mathrm{wt} \%$ of hydrogen and displays significantly improved hydride formation kinetics as compared to $\mathrm{MgH}_{2}$ [9]. $\mathrm{Mg}-\mathrm{Ni}$ alloys can be prepared as thin films which readily react with hydrogen at room temperature and moderate $\mathrm{H}_{2}$ pressure $\left(\leq 10^{5} \mathrm{~Pa} \mathrm{H}_{2}\right)$ when capped with $\mathrm{Pd}$ [10]. However, the enthalpy of $\mathrm{Mg}_{2} \mathrm{NiH}_{4}$ formation $\Delta \mathrm{H}=-64 \mathrm{~kJ}\left(\mathrm{~mol} \mathrm{H}_{2}\right)^{-1}$ is still too negative to make this an applicable material, In order to desorb hydrogen at 1 bar and room temperature an enthalpy of $-40 \mathrm{~kJ} /\left(\mathrm{mol} \mathrm{H} \mathrm{H}_{2}\right)$ is required, assuming that the entropy of the reaction is solely determined by the condensation of hydrogen $\left(\Delta \mathrm{S}^{\ominus} \cong\right.$ 
$\left.-130 \mathrm{~J}\left(\mathrm{~K} \mathrm{~mol} \mathrm{H}_{2}\right)^{-1}\right)$.

Using a combinatorial thin film approach called hydrogenography, Gremaud et al. investigated the enthalpy of hydride formation in the quaternary $\mathrm{Mg}-\mathrm{Ni}-\mathrm{Ti}-\mathrm{H}$ system [11]. They showed that the enthalpy of hydride formation for $\mathrm{Mg}_{\mathrm{y}} \mathrm{Ni}_{\mathrm{z}} \mathrm{Ti}_{1-\mathrm{y}-\mathrm{z}} \mathrm{H}_{\mathrm{x}}$ $(0.45 \leq \mathrm{y} \leq 0.70$ and $0.20 \leq \mathrm{z} \leq 0.40)$ reaches the desired $-40 \mathrm{~kJ}\left(\mathrm{~mol} \mathrm{H}_{2}\right)^{-1}$. However, the entropy of hydrogenation of Mg-Ni-Ti decreases to about $-90 \mathrm{~J} \cdot \mathrm{K}^{-1} \cdot \mathrm{mol}^{-1} \mathrm{H}_{2}$. As a result, the addition of $\mathrm{Ti}$ to the Mg-Ni system hardly affects the equilibrium pressure as is evident from the Van 't Hoff equation.

Based on DFT calculations Broedersz et al proposed that the destabilization of Mg-Ni-H by Ti doping is related to the formation of a mixture of $\mathrm{Mg}_{2} \mathrm{Ni}$ and $\mathrm{Ti}-\mathrm{Ni}$ in the as-deposited state, which transform into a single meta-stable Ti-doped $\mathrm{Mg}_{2} \mathrm{NiH}_{4}$ phase upon hydrogenation [12]. However, up to now no experimental evidence is available on the phases/species present in the Mg-Ni-Ti systems neither in the as-deposited state nor in the hydrogenated state. The quasi-amorphous nature of this material is very demanding on the micro-analytical tools to be used to investigate the structural and compositional nature of this material. Here we present the results on the local structure of Mg-Ni-Ti-(H) as investigated by EXAFS and relate these results to the theoretical data of Broedersz.

Extended X-ray Absorption Spectroscopy (EXAFS) is a powerful element-specific tool to determine the local structure around an absorber atom and has the advantage that it does not require long range order [13]. Typically, from EXAFS data we obtain the type and number of neighbors and their distance to the absorber 
atoms. In this paper, we use Ni-K edge and Ti-K edge EXAFS to investigate the local coordination of $\mathrm{Ni}$ and $\mathrm{Ti}$ atoms in order to determine the local structure in Ti-doped Mg-Ni-alloys both in the as-prepared and hydrogenated state. Using magnetron co-sputtering we prepared $\mathrm{Mg}-\mathrm{Ni}-\mathrm{Ti}$ thin films in which, based on the $\mathrm{Mg}_{2} \mathrm{Ni}$ stoichiometry, either part of the Mg was replaced by $\mathrm{Ti}\left(\mathrm{Mg}_{2-\mathrm{y}} \mathrm{NiTi}_{\mathrm{y}}\right)$ or part of the $\mathrm{Ni}$ was replaced by $\mathrm{Ti}\left(\mathrm{Mg}_{2} \mathrm{Ni}_{1-\mathrm{x}} \mathrm{Ti}_{\mathrm{x}}\right)$.

\section{EXPERIMENTAL}

Metallic Mg-Ni-Ti films were prepared in an AJA 7-gun ultra-high vacuum dc/rf magnetron co-sputtering system with a base pressure of $10^{-7} \mathrm{~Pa}$. The $\mathrm{Mg}$, Ti and $\mathrm{Ni}$ off-axis sputter guns are positioned every $120^{\circ}$ on a circle. The films were deposited on glassy carbon SIGRADUR ${ }^{\circledR}$ substrate of $100 \mu \mathrm{m}$ thickness at room temperature. First, a $5 \mathrm{~nm} \mathrm{Cr}$ layer is deposited on the surface of the carbon substrate as a cohesion layer. Next a Mg-Ni-Ti film of about $400 \mathrm{~nm}$ was deposited which was finally capped with a $10 \mathrm{~nm}$ Pd layer. The latter prevents oxidation and promotes hydrogen dissociation. These samples were used for the EXAFS studies; for the hydrogenography measurement an optically transparent glass substrate was used and a much thinner (50 nm) Mg-Ni-Ti layer was capped with 20 nm Pd.

The EXAFS spectra were recorded for the nickel K-edge $(8333 \mathrm{eV})$ at beamline $\mathrm{C}$ and for the titanium K-edge (4966 eV) at beamline A1 of the DORIS III storage ring in the Deutsches Elektronen-Synchrotron (DESY), Hamburg. The beamline is equipped with a Si (111) double-crystal monochromator, which is detuned to $60 \%$ of 
the Bragg peak intensity to suppress higher harmonics. Samples were measured in transmission at room temperature, in He flow for the as-deposited or $5 \% \mathrm{H}_{2} / \mathrm{He}$ mixture flow for hydrogenated films. In each measurement a pile of 14 films cut from a larger sample were inserted into the beam, in order to obtain a sufficiently high signal to noise ratio. Three consecutive ionization chambers allow to simultaneously measure the absorption spectra of both the sample and a reference $\mathrm{Ni}$ foil.

In order to calibrate the $\mathrm{Ni}-\mathrm{Ni}, \mathrm{Ni}-\mathrm{Ti}$ and $\mathrm{Ni}-\mathrm{Mg}$ references, we use a $7 \mu \mathrm{m}$ thick Ni foil (99.99\%), 5um thick Ti foil (99.99 \%), $800 \mathrm{~nm}$ thick sputtered $\mathrm{Mg}_{2} \mathrm{Ni}$ and $\mathrm{Ti}_{2} \mathrm{Ni}$ thin films, respectively.

The EXAFS data were extracted from the measured absorption spectra with XDAP [14]. At least three scans for each sample were averaged. The edge-energy was defined as the energy at which the first derivative of the absorption spectrum showed a maximum, and used to calibrate the energy scale by comparison with the reference $\mathrm{Ni}$ and Ti foils. A cubic spline was used to substract a smooth atomic background function, to extract the EXAFS oscillations from the absorption spectrum [15]. The intensity of the absorption was normalized using the background intensity $50 \mathrm{eV}$ after the edge. The quality of the fit was checked by applying $\mathrm{k}^{1}$ and $\mathrm{k}^{3}$ weightings, using the difference file technique in real space [13]. For calculating EXAFS spectra to evaluate different structural models, we used IFEFFIT [16]. The theoretical backscattering amplitude and phase shift functions were calculated by the FEFF6 code [17].

X-ray diffraction patterns were measured in a $\theta-2 \theta$ configuration, with a Bruker 
D8 Discover x-ray diffractometer ( $\mathrm{Cu}-\mathrm{K} \alpha, \lambda=1.5148 \AA$ ) $)$ equipped with an Euler sample goniometer, a 2 D HI-STAR area detector and GADDS software. A beryllium dome allows in-situ measurements during hydrogenation of the films at room temperature in a hydrogen pressure of $10^{5} \mathrm{~Pa}$.

Hydrogen-loading isotherms were measured between 304 and $363 \mathrm{~K}$ by means of hydrogenography [11], an optical technique that detects the amount of light transmitted through a thin film while increasing the hydrogen pressure at a fixed temperature. The pressure-optical transmission-isotherms (PTIs) obtained in this way can be directly related to the standard pressure-composition-isotherms conventionally used to measure the plateau pressure of metal hydrides. By plotting the equilibrium pressure as a function of the reciprocal temperature, the enthalpy and entropy of formation are obtained through a Van 't Hoff analysis. Details of the hydrogenography experimental setup and analysis can be found in Ref. [11].

\section{RESULTS}

\section{III-1. Hydrogenography}

Figure 1a gives the absorption pressure-optical-transmission-isotherms (PTIs) of $\mathrm{Mg}_{2-\mathrm{y}} \mathrm{NiTi}_{\mathrm{y}}$ (where Ti substitutes $\mathrm{Mg}$ and $\mathrm{y}=0,0.25$ and 0.5 ) and $\mathrm{Mg}_{2} \mathrm{Ni}_{1-\mathrm{x}} \mathrm{Ti}_{\mathrm{x}}$ (where Ti substitutes $\mathrm{Ni}$ and $\mathrm{x}=0,0.25$ and 0.5 ) measured at $\mathrm{T}=333 \mathrm{~K}$. Here, the optical transmission $\mathrm{T}$ is normalized by the transmission in the metallic state $T_{M}$. The isotherms are measured after two hydrogenation cycles and are found to be stable on further cycling. For all of the samples, the transmission increases with an increase of pressure. However, the isotherms exhibit a plateau region where the metallic phase is 
in equilibrium with a hydrogenated phase (the so-called $\alpha-\beta$ coexistence region). The samples were measured at four temperatures, $304 \mathrm{~K}, 333 \mathrm{~K}, 348 \mathrm{~K}$ and $363 \mathrm{~K}$. In this way, the equilibrium pressure at these four different temperatures is obtained. The relation between the pressure and temperature is plotted for the various compositions in figure 1b. Using the Van 't Hoff equation, the hydrogenation enthalpy and entropy are obtained and the values are listed in Table 1 . Clearly the enthalpy of hydrogenation is in the desired range of $-40 \mathrm{~kJ} /\left(\mathrm{mol} \mathrm{H}_{2}\right)$. Unfortunately, the equilibrium pressure at room temperature is in the range of 250 670 $\mathrm{Pa}$, much lower than the expected value of $10^{5} \mathrm{~Pa}$. This is due to the fact that also the entropy of formation is reduced from its ideal value of $-130 \mathrm{~J} / \mathrm{mol} . \mathrm{K}$, as can be seen from the Van 't Hoff analysis. The reason for this enthalpy entropy correlation is still an enigma.

\section{III-2. XRD structural analysis}

To understand the thermodynamic behavior in relation to the structure XRD was used to characterize these samples (Figure 2). In the as-prepared state (see Figure 2 (a)), for pure $\mathrm{Mg}_{2} \mathrm{Ni}$, we only find one peak in the range considered at about 41 degrees. Attributing this peak to the $\mathrm{Mg}_{2} \mathrm{Ni}$ (006) reflection, we conclude that the c-axis of the hexagonal lattice is preferentially oriented out-of-plane. On substituting $\mathrm{Mg}$ by $\mathrm{Ti}$, the (006) peak disappears and other $\mathrm{Mg}_{2} \mathrm{Ni}$ peaks such as (110), (103) and (200) appear suggesting a more random orientation of the lattice. In addition, other peaks are observed which indicate the presence of either TiNi (101) or $\mathrm{TiNi}_{3}$ (103). In the 
$\mathrm{Mg}_{2} \mathrm{Ni}_{1-\mathrm{y}} \mathrm{Ti}_{\mathrm{y}}$ samples, we find no obvious peaks for $\mathrm{y}=0.25$ suggesting an amorphous phase. For $\mathrm{y}=0.5$ we find only one sharp peak either belonging to $\mathrm{Mg}_{2} \mathrm{Ni}$ (110) or $\mathrm{Mg}$ (002).

Figure 2(b) shows the XRD patterns in the hydrogenated state. For pure $\mathrm{Mg}_{2} \mathrm{Ni}$, after hydrogenation, the $\mathrm{Mg}_{2} \mathrm{NiH}_{4}$ peak (220) intensity decreases and also broadens, indicating an increase of disorder in the hydrogenated state. In the hydrogenated state $\mathrm{Mg}_{2-\mathrm{y}} \mathrm{NiTi}_{\mathrm{y}}\left(\mathrm{y}=0.25\right.$ and 0.5 ), we find two peaks, one might belong to $\mathrm{Mg}_{2} \mathrm{NiH}_{4}(112)$, and the other is unidentified. The hydrogenated state of both the $y=0.25$ and $y=0.5$ substitutions of $\mathrm{Mg}_{2} \mathrm{Ni}_{1-\mathrm{y}} \mathrm{Ti}_{\mathrm{y}}$ appear to be X-ray amorphous. The Mg peak (002) disappears after hydrogenation due to the formation of $\mathrm{MgH}_{2}$ [18]. Due to the low crystallinity of the thin film samples, we need another technique to elucidate the structural nature of both the metallic and the hydrogenated state. For this purpose we used EXAFS since that technique does not require long range order in the samples.

\section{III-3 EXAFS}

Fig. 3(a) shows background subtracted Ni K-edge EXAFS data of undoped $\mathrm{Mg}_{2} \mathrm{Ni}$ in the as-prepared and hydrogenated state. An acceptable signal to noise ratio was obtained up to $\mathrm{k}=10 \AA$ Á. Figure 3(b) displays the $k^{3}$-weighted Fourier transformed (FT) data of the same samples. Both FTs show a signal at about $2.2 \AA$, of which the lower intensity is from the hydrogenated sample.

A representative example of the fitted data of the hydrogenated $\mathrm{Mg}_{2} \mathrm{Ni}$ film is shown in Fig. 4. The EXAFS data was effectively fitted with scattering due to 
magnesium and nickel atoms around the absorbing Ni-atom (Table 2). The number of independent parameters used in all cases is lower than the maximum value set by the Nyquist theorem [19] in this case 8 parameters were used while 9 were allowed.

\section{III-3-1 As-prepared $\mathrm{Mg}_{2} \mathrm{Ni}$}

From Table 2, it can be seen that in the as-prepared $\mathrm{Mg}_{2} \mathrm{Ni}$ film, $\mathrm{Ni}-\mathrm{Ni}$ and Ni-Mg shells are located at distances of 2.54 and $2.63 \AA$ with a coordination of 2.1 and 6.2, respectively. After hydrogenation, the Ni-Mg coordination number decreases to 5.6 while the Ni-Mg distance remains unaffected. The Ni-Ni contribution disappears completely after hydrogenation. Moreover, after hydrogenation, the Debye-Waller factor $\left(\Delta \sigma^{2}\right)$ for the Ni-Mg shell is more than twice that of the as-prepared $\mathrm{Mg}_{2} \mathrm{Ni}$ films. This means a more disordered sample is formed on hydrogenation which is in agreement with the decreased XRD intensity shown earlier [20]. A possible reason for the increase in disorder might be the change in crystal structure from hcp $\mathrm{Mg}_{2} \mathrm{Ni}$ to monoclinic $\mathrm{Mg}_{2} \mathrm{NiH}_{4}$.

On basis of the crystallographic data of $\mathrm{Mg}_{2} \mathrm{Ni}$ [21], Ni should be surrounded by 2 Ni atoms at $2.60 \AA$ and by $8 \mathrm{Mg}$ atoms at $2.66 \AA$. Our fitting indicates a Ni-Mg coordination number of 6.2 which is significantly lower than the value for bulk crystalline $\mathrm{Mg}_{2} \mathrm{Ni}$ of 8 . This suggests that at least part of the as-deposited $\mathrm{Mg}_{2} \mathrm{Ni}$ film is nanocrystalline or amorphous [20] in the latter case resulting in a high Debye Waller factor which can result in an underestimation of the coordination number. The presence of $2.1 \mathrm{Ni}$ atoms at a distance of $2.54 \AA$, s which is higher than the expected 
1.6 based on $\mathrm{Ni} / \mathrm{Mg}$ stoichiometry, may indicate the presence of a small amount of $\mathrm{MgNi}_{2}$ (table 1 supplemental data).

To elucidate the structure of $\mathrm{Mg}_{2} \mathrm{Ni}$ after hydrogenation we compared the structural parameters found by EXAFS (Table 2) with those of the crystallographic data of the two forms of $\mathrm{Mg}_{2} \mathrm{NiH}_{4}$ (table 1 supplemental information). Though the match is not perfect we believe that our sample resembles the structure of the low temperature monoclinic form of $\mathrm{Mg}_{2} \mathrm{NiH}_{4}$. We could not observe any Ni-Ni scattering in the fitting range which would be expected for the high temperature cubic structure. The coordination number we find for Ni-Mg is 5.6, which is lower than the expected value (7) of the monoclinic structure. This we attribute to a poor crystallinity as discussed above. The Ni-Mg distance is $2.64 \AA$, which is consistent with a previous result in literature (2.63 $\AA$ [20]), but lower than the expected value of $2.73 \AA$.

III-3-3 Doped $\mathrm{Mg}_{2} \mathrm{Ni}$ in the as-deposited and hydrogenated state: Ni-edge

Now we turn to Ti doped films and first discuss the samples in which Ti replaces part of the Mg.

\section{$\mathrm{Mg}_{1.75} \mathrm{NiTi}_{0.25}$}

For the as-prepared state of $\mathrm{Mg}_{1.75} \mathrm{NiTi}_{0.25}, 5.6 \mathrm{Mg}$ neighbors at $2.72 \AA$ and 0.96 Ti neighbors at $2.46 \AA$ were found surrounding Ni (Table 2). By comparing these results with the expected values for different $\mathrm{Ni}-\mathrm{Ti}$ and $\mathrm{Ni}-\mathrm{Mg}$ compounds (Table 1 supplemental) we conclude that the Ti contribution comes from Ti-Ni intermetallics, although no perfect match with any of the intermetallics ( $\mathrm{TiNi}, \mathrm{TiNi}_{3}$ or $\mathrm{Ti}_{2} \mathrm{Ni}$ ) could 
be found.

The $\mathrm{Mg}$ contribution originates from $\mathrm{Mg}_{2} \mathrm{Ni}$ contribution, although the $\mathrm{Ni}-\mathrm{Mg}$ distance is a little bit longer than that in bulk $\mathrm{Mg}_{2} \mathrm{Ni}$ indicating some heterogeneity in the sample.

The fact that no Ni-Ni contribution was obtained is in accordance with Farangis's results [22] who measured $\mathrm{Mg}_{0.87} \mathrm{Ni}_{0.13}$ and $\mathrm{Mg}_{0.67} \mathrm{Ni}_{0.33}$ thin films in metallic state from the Mg K-edge and did not observe any Mg-Mg scattering. They ascribed that observation to the amorphous nature of their samples resulting in a high Debye Waller factor and underestimation of the coordination number. This may also be the explanation in our case for the highly disordered $\mathrm{Ni}$ atoms, given the high disorder parameter and the random growth direction found in the XRD pattern.

After hydrogenation, we find a coordination of $5.6 \mathrm{Mg}$ atoms at a distance of 2.6 ̊, while $1.4 \mathrm{Ti}$ are surrounding $\mathrm{Ni}$ at a distance of $2.65 \AA$. These data are compatible with the formation of a Ti-Ni based hydride ( $\mathrm{TiNiH}$ [23] or $\mathrm{Ti}_{2} \mathrm{NiH}$ [24]) or the formation of a Ti-doped $\mathrm{Mg}_{2} \mathrm{NiH}_{4}$ structure as predicted by the DFT calculation for $\mathrm{Mg}_{2-\mathrm{y}} \mathrm{NiTi}_{\mathrm{y}} \mathrm{H}_{4}(\mathrm{y}=0.25)$ [12]. However, the Ni-Ti distance in the Ti-Ni hydrides is much shorter $(<2.6)$ than we find here. The DFT calculation predicted that the $\mathrm{Ti}$ substitutes for $\mathrm{Mg}_{1}(8 \mathrm{f})$ and $\mathrm{Mg}_{3}(4 \mathrm{e})$ in the $\mathrm{Mg}_{2} \mathrm{NiH}_{4}$ structure, resulting in a $\mathrm{Ni}-\mathrm{Ti}$ distance of 2.61, 2.64, 2.68, 2.70 and 2.94, which is in good agreement with our findings.

\section{$\mathrm{Mg}_{1.5} \mathrm{NiTi}_{0.5}$}


Figure 5 gives the $k^{3}$ weighted Fourier transformed EXAFS data of $\mathrm{Mg}_{1.5} \mathrm{NiTi}_{0.5}$ both in the as-prepared state (solid line) and hydrogenated state (dashed line). The best fitting results (shown in table 2) used one shell of Ti and one shell of Mg. From table 2, it can be seen that the coordination number for Ti surrounding $\mathrm{Ni}$ is 3.2 in the as-prepared state of $\mathrm{Mg}_{1.5} \mathrm{NiTi}_{0.5}$. Again we conclude that a Ti-Ni compound is formed on deposition, without being able to distinguish exactly which Ti-Ni intermetallic is formed. The Ni-Mg coordination is about 8 , and the value for the distance we find is close to that in pure $\mathrm{Mg}_{2} \mathrm{Ni}$. Therefore, for the as-prepared state of $\mathrm{Mg}_{1.5} \mathrm{NiTi}_{0.5}$, we propose that the film is composed of two phases, $\mathrm{Mg}_{2} \mathrm{Ni}$ and a $\mathrm{Ti}-\mathrm{Ni}$ intermetallic compound.

In the low temperature $\mathrm{Mg}_{2} \mathrm{NiH}_{4}$ phase, there are three inequivalent $\mathrm{Mg}$ sites while all Ni atoms can be considered to be equivalent [25]. On the basis of DFT the structure of $\mathrm{Mg}_{1.5} \mathrm{NiTi}_{0.5} \mathrm{H}_{4}$ was derived in Ref. 12 (See Table 2 in supplementary materials). According to the DFT calculations [10], the $\operatorname{Mg}_{1}(8 \mathrm{f})$ and $\mathrm{Mg}_{3}(4 \mathrm{f})$ sites are found to be $2.9 \mathrm{~kJ}$ (mol f.u.) ${ }^{-1}$ more favorable for Ti substitution than the $\mathrm{Mg}_{2}(8 \mathrm{f})$ site. In addition, in that paper a tendency of Ti to cluster around Mg was observed. In order to find experimentally which $\mathrm{Mg}$ is substituted by $\mathrm{Ti}$, we used different models (different $\mathrm{Ti}$ positions) to compare the theoretical data and experimental data. We built a model assuming that three $\mathrm{Ti}$ atoms substitute for Mg around a single Ni atom. After that, the ATOMS package in IEFFIT [17] was applied to get the atomic distances. Then, three $\mathrm{Ti}$ atoms are directly placed at the corresponding positions, such as $\mathrm{Mg}_{1}(8 \mathrm{f})$ and $\mathrm{Mg}_{3}(4 \mathrm{f})$. Note, that in this case we compare the experimentally 
observed data, to the structural data observed with DFT. Table 3 gives the theory, experiment, model and IFEFFIT results of $\mathrm{Mg}_{1.5} \mathrm{NiTi}_{0.5} \mathrm{H}_{4}$. For model 1, we consider that $\mathrm{Ti}$ atoms located at $2 \mathrm{Mg} 3(4 \mathrm{e})$ and $1 \mathrm{Mg1(8f)}$ positions. In this way, we find a $\mathrm{Ti}$ coordination number of 3 and a Ni-Ti distance of $2.71 \AA$. The Mg coordination number is 4 and the $\mathrm{Mg}$ is located at a distance of $2.66 \AA$. The other option worked out in model 2 is that $\mathrm{Ti}$ atoms are located at the two Mg1(8f) and the $\operatorname{Mg3}(4 \mathrm{e})$ positions. Again the Ti coordination number is 3 and the distance of Ni-Ti is $2.61 \AA$. The Mg coordination number equals 4, and the atoms are located at a distance of 2.72 Å. Comparing the experimental results to both model 1 and model 2, it is easily seen that model 2 is much closer to the experimental results. The schematics of the $\mathrm{Mg}_{2} \mathrm{NiH}_{4}$ and $\mathrm{Mg}_{1.5} \mathrm{NiTi}_{0.5} \mathrm{H}_{4}$ structures are given in Figure 6 .

Fig. 7 shows the magnitude of the phase-uncorrected Fourier transformed $k^{3}$-weighted $\chi(\mathrm{k})$, both the experimental data and the fit, for $\operatorname{Mg}_{1.5} \mathrm{NiTi}_{0.5} \mathrm{H}_{4}$. We assume here that in Ti-doped $\mathrm{Mg}_{2} \mathrm{NiH}_{4}$ Ti substitutes for two $\mathrm{Mg}_{1}(8 \mathrm{f})$ and one $\mathrm{Mg}_{3}(4 \mathrm{e})$ atoms in the monoclinic structure. Fitting was performed within 1.5-3.0 $\AA$ corresponding to the following n-degenerate shells of Ni nearest-neighbor linkages: n=3 for Ni-Ti and 4 for Ni-Mg pairs. The fitting results are listed in table 2. From Fig. 7 and table 3, the FEFF model 2 fits very well with the experimental results. The difference in coordination between the FEFF model and experimental fit means that Ti substitutes somewhat less than $3 \mathrm{Mg}$ atoms in the $\mathrm{Mg}_{2} \mathrm{NiH}_{4}$-like monoclinic structure. 


\section{$\mathrm{Mg}_{2} \mathrm{Ni}_{0.5} \mathrm{Ti}_{0.5}$ and $\mathrm{Mg}_{2} \mathrm{Ni}_{0.75} \mathrm{Ti}_{0.25}$}

The second part of Table 2 gives the fitting results of $\mathrm{Mg}_{2} \mathrm{Ni}_{0.75} \mathrm{Ti}_{0.25}$ and $\mathrm{Mg}_{2} \mathrm{Ni}_{0.5} \mathrm{Ti}_{0.5}$ both for the as-prepared and hydrogenated states. For the as-prepared state, the phases again appear to consist of $\mathrm{Mg}_{2} \mathrm{Ni}$ and $\mathrm{Ti}-\mathrm{Ni}$ intermetallics. For the hydrogenated $\mathrm{Mg}_{2} \mathrm{Ni}_{0.75} \mathrm{Ti}_{0.25}$, there is on the average $0.86 \mathrm{Ti}$ atoms around each $\mathrm{Ni}$ atom. It means that there is a slight $\mathrm{Ti}$ substitution for $\mathrm{Mg}$ in the hydrogenated state. For the hydrogenated $\mathrm{Mg}_{2} \mathrm{Ni}_{0.50} \mathrm{Ti}_{0.50}$, the Ti coordination numbers increases to 2.64. So again part of the Mg is substituted by Ti even though Ti was supposed to take the place of Ni. We built a model in which Ti substituted $2 \mathrm{Mg}_{1}$ (8f) and $1 \mathrm{Mg}_{3}(4 \mathrm{e}$ ) atoms to fit this substitution of Mg (not shown here). Since there will be excessive Mg left, $\mathrm{MgH}_{2}$ will form in addition to the Ti-doped $\mathrm{Mg}_{2} \mathrm{NiH}_{4}$ phase, resulting in two plateaus. Indeed, large parts of the Mg-Ni-Ti-H phase diagram show a double plateau, as indicated by the dark regions in Ref.11.

\section{III-3-3 Doped $\mathrm{Mg}_{2} \mathrm{Ni}$ in the as-deposited and hydrogenated state: Ti K-edge}

To find out which kind of Ti-Ni intermetallics were formed in the as-deposited state, we also measured the Ti K-edge. The fitting results for the as-prepared state are listed in table 4. We find that $\mathrm{Ti}$ is surrounded by $3.0 \mathrm{Ni}$ neighbors at $2.47 \AA$ and $3.2 \mathrm{Ti}$ neighbors at $2.55 \AA$. By comparing these values to those of the reference compounds, i.e. $\mathrm{TiNi}, \mathrm{Ti}_{2} \mathrm{Ni}$ and $\mathrm{TiNi}_{3}$, the structure of the sample is most similar to that of $\mathrm{TiNi}_{3}$ although the coordination numbers are lower than the expected values. The smaller coordination number is probably due to the small grain size of this Ni rich compound. 
The Ti-Ni distance agrees well with the value obtained from Ni K-edge. The difference is that Ni has $1 \mathrm{Ti}$ neighbor from Ni K-edge, but Ti has $3 \mathrm{Ni}$ neighbors from Ti K-edge. This can be understood if we assume that the major phase $\mathrm{Mg}_{2} \mathrm{Ni}$ coexists with the minority phase of nano clusters of $\mathrm{TiNi}_{3}$.In this case, there will be more $\mathrm{Mg}$ atoms but less $\mathrm{Ti}$ atoms surrounding $\mathrm{Ni}$ atoms because of the majority phase of $\mathrm{Mg}_{2} \mathrm{Ni}$ and minority phase of $\mathrm{TiNi}_{3}$, while $\mathrm{Ti}$ is the central atom, there will be only $\mathrm{Ni}$ and Ti.

When increasing the Ti content, for the as-prepared state of $\mathrm{Mg}_{1.5} \mathrm{NiTi}_{0.5}$, no $\mathrm{Ti}$ coordination of the $\mathrm{Ti}$ was found, and only $7.0 \mathrm{Ni}$ neighbors were found surrounding Ti,. These values are similar to those for TiNi though in that case the Ti-Ni coordination number is 8 . This means that TiNi is present as nanocrystallites or clusters, because only the first shell of Ni was obtained. For the as-prepared state of $\mathrm{Mg}_{2} \mathrm{Ni}_{0.75} \mathrm{Ti}_{0.25}, 7.0 \mathrm{Ni}$ neighbors at $2.46 \AA$ and $1.2 \mathrm{Ti}$ neighbors at $2.76 \AA$ were obtained for the Ti atoms. This is an indication that TiNi is formed, although these values are lower than those for bulk crystalline TiNi. For Ti in the as-prepared state of $\mathrm{Mg}_{2} \mathrm{Ni}_{0.5} \mathrm{Ti}_{0.5}, 8.1 \mathrm{Ni}$ neighbors at $2.50 \AA$ and $3.3 \mathrm{Ti}$ neighbors at $2.82 \AA$ were obtained, also indicating the formation of TiNi. When comparing the samples with $\mathrm{y}=0.25$ and 0.5 in $\mathrm{Mg}_{2} \mathrm{Ni}_{1-\mathrm{y}} \mathrm{Ti}_{\mathrm{y}}$, an increase in the number of neighbors as well as the distances of $\mathrm{Ti}$ and $\mathrm{Ni}$ with increasing Ti substitution is observed. This indicates that the TiNi crystal structure formed. But this structure is quite disordered as indicated by the higher Debye-Waller factor.

To know the local structure of $\mathrm{Ti}$ in the hydrogenated state, we also tried to 
measure the Ti K-edge absorption spectra for the hydrogenated samples, but no adequate signal to noise ratio could be obtained. A figure of the hydrogenated state for Ti K-edge measured in fluorescence mode is shown in Figure 8.

\section{DISCUSSION}

We used EXAFS to study the Ti-doped $\mathrm{Mg}_{2} \mathrm{Ni}$ system in both the as-prepared and hydrogenated state. Our results generally confirm the outcome of previous DFT calculations, namely that $\mathrm{Mg}_{2} \mathrm{Ni}$ and $\mathrm{Ti}-\mathrm{Ni}$ intermetallics coexist in the as-prepared state, and that after hydrogenation Ti-doped $\mathrm{Mg}_{2} \mathrm{NiH}_{4}$ is formed, with Ti substituting for Mg. We find that in the as-prepared state $\mathrm{TiNi}_{3}$ and $\mathrm{TiNi}$ are formed for $\mathrm{y}=0.25$ and $\mathrm{y}=0.5$ in the Mg-substituted $\mathrm{Mg}_{2-\mathrm{y}} \mathrm{NiTi}_{\mathrm{y}}$ case, while in Ti substituted $\mathrm{y}=0.25$ and $\mathrm{y}=0.5 \mathrm{Mg}_{2} \mathrm{Ni}_{1-\mathrm{y}} \mathrm{Ti}_{\mathrm{y}}$ state, the TiNi intermetallic compound is formed. No indication for the formation of any metallic Ti was found for the as-prepared state, while in the hydrogenated state no sign was found for the formation of $\mathrm{TiH}_{2}$ or any $\mathrm{Ti}-\mathrm{Ni}$ intermetallic hydride. Also, no alternative structure for Ti-doped $\mathrm{Mg}_{2} \mathrm{NiH}_{4}$ was found which could explain the EXAFS results.

Although our EXAFS results generally confirm the DFT calculations reported in literature, some experimental results are at variance with them. While for $\mathrm{Mg}_{2-\mathrm{y}} \mathrm{NiTi}_{\mathrm{y}}$ with $(y \leq 0.25)$ our EXAFS confirms the DFT results, for the higher Ti-doped samples at the hydrogenated state (e.g. $\mathrm{Mg}_{1.5} \mathrm{NiTi}_{0.5}$ hydride) there appears to be a preference for $\mathrm{Ti}$ to cluster around the Ni even to a larger extent than expected. 
In the Mg-Ni-Ti ternary system, we have found a wide range of compositions with an enthalpy value of about $-40 \mathrm{~kJ} /\left(\mathrm{mol} \mathrm{H}_{2}\right)$. However, the entropy is about $-90 \mathrm{~J}$ $\mathrm{K}^{-1}\left(\mathrm{~mol} \mathrm{H}_{2}\right)^{-1}$ [26] while close to $-131 \mathrm{~kJ} /\left(\mathrm{mol} \mathrm{H}_{2}\right)$, the entropy of gaseous hydrogen, would be expected). As a result, the equilibrium pressure is not as high as we would have hoped for. Qualitatively, the reduction in entropy of formation of the hydride can have various reasons. First of all, the mixing entropy of the $\mathrm{Mg}_{2} \mathrm{Ni}$ and $\mathrm{Ti}-\mathrm{Ni}$ phases may have some effect on the overall value of $\Delta \mathrm{S}$. Second, the Ti-doped $\mathrm{Mg}_{2} \mathrm{NiH}_{4}$ is a metastable phase which has probably has a higher entropy than that of pure $\mathrm{Mg}_{2} \mathrm{NiH}_{4}$ [27]. The third reason maybe an increase in configurational entropy on Ti doping. However, the quality of the structural information is insufficient to make any concluding statement at this stage.

\section{CONCLUSIONS}

Investigating the structure of Ti-doped $\mathrm{Mg}_{2} \mathrm{Ni}$ thin films in both the as-deposited and hydrogenated state, we find evidence confirming earlier DFT calculations. The as-prepared state is composed of $\mathrm{Mg}_{2} \mathrm{Ni}$ and $\mathrm{Ti}-\mathrm{Ni}$ intermetallics. In the hydrogenated state we observe a strong tendency for $\mathrm{Ti}$ to substitute for the $\mathrm{Mg}$ in the $\mathrm{Mg}_{2} \mathrm{NiH}_{4}$ structure. In the $\mathrm{Mg}_{2} \mathrm{Ni}_{1-\mathrm{y}} \mathrm{Ti}_{\mathrm{y}} \mathrm{H}_{\mathrm{x}}$ hydrides ( $\mathrm{y}=0.25$ and 0.5 ), Ti substitutes not only $\mathrm{Ni}$ but also Mg. The presence of the Ti-doped hydride is quite remarkable since this structure is meta-stable with respect to segregation into $\mathrm{Mg}_{2} \mathrm{NiH}_{4}$ and $\mathrm{TiH}_{2}$ [12]. Given the stability of the hydrogenography plateau on cycling, we conclude that the quasi-amorphous nature is most likely responsible for the stabilization of the $\mathrm{Ti}$ 
substitution in the hydride phase. Clearly, a further microstructural analysis probing the crystallinity and composition at the nanoscale is highly warranted to obtain a full structural understanding. The relation between the Ti substitution and the enthalpy entropy compensation effect remains, however, an enigma.

\section{ACKNOWLEDGMENTS}

The authors would like to acknowledge the financial support from the NWO-ACTS Sustainable Hydrogen program, and NWO-Vidi (PdJ). In addition the project has received grants of HASYLAB under the number I-200801031 EC and II-20090124 EC.

\section{References}

[1] Züttel A. Materials for hydrogen storage. Mater Today 2003;9:24-33.

[2] Huot J, Liang G, Schulz R. Mechanically alloyed metal hydride systems. Appl Phys A 2001;72:187-195.

[3] Krozer A, Kasemo B. Hydrogen uptake by Pd-coated Mg:

absorption-decomposition isotherms and uptake kinetics. J Less-Common Met 1990;160:323-42.

[4] Liang G, Huot J, Boily S, Van Neste A, Schulz R. Catalytic effect of transition metals on hydrogen sorption in nanocrystalline ball milled $\mathrm{MgH}_{2}-\mathrm{Tm}(\mathrm{Tm}=\mathrm{Ti}, \mathrm{V}$, Mn, Fe and Ni) systems. J Alloys Compd 1999;292:247-52.

[5] Yang H, Yuan H, Ji J, Sun H, Zhou Z, ZhangY. Characteristics of $\mathrm{Mg}_{2} \mathrm{Ni}_{0.75} \mathrm{M}_{0.25}$ 
( $\mathrm{M}=\mathrm{Ti}, \mathrm{Cr}, \mathrm{Mn}, \mathrm{Fe}, \mathrm{Co}, \mathrm{Ni}, \mathrm{Cu}$ and Zn) alloys after surface treatment. J Alloys Compd 2002;330-332:640-44.

[6] Shang CX, Bououdina M, Song Y, Guo ZX. Mechanical alloying and electronic simulations of $\left(\mathrm{MgH}_{2}+\mathrm{M}\right)$ systems $(\mathrm{M}=\mathrm{Al}, \mathrm{Ti}, \mathrm{Fe}, \mathrm{Ni}, \mathrm{Cu}$ and $\mathrm{Nb})$ for hydrogen storage. Int J Hydrogen Energy 2004;29:73-80.

[7] Bogerd R, Adelhelm P, Meeldijk JH, De Jong KP, De Jongh PE, The structural characterization and $\mathrm{H}_{2}$ sorption properties of carbon-supported $\mathrm{Mg}_{1-\mathrm{x}} \mathrm{Ni}_{\mathrm{x}}$ nanocrystallites. Nanotechnology 2009;20:204019.

[8] Hanada N, Ichikawa T, Fujii H. Catalytic effect of nanoparticle 3d-transition metals on hydrogen storage properties in magnesium hydride $\mathrm{MgH}_{2}$ prepared by mechanical milling. J Phys Chem B 2005;109:7188-94.

[9] Reilly JJ, Wiswall RH, Reaction of hydrogen with alloys of magnesium and nickel and the formation of $\mathrm{Mg}_{2} \mathrm{NiH}_{4}$. Inorg Chem 1968;7:2254-56.

[10] Richardson TJ, Slack JL, Armitage RD, Kostecki R, Farangis B, Rubin MD, Switchable mirrors based on nickel-magnesium films. Appl Phys Lett 2001;78:3047.

[11] Gremaud R, Broedersz C, Borsa DM, Borgschulte A, Mauron P, Schreuders H, et al. Hydrogenography: An optical combinatorial method to find new light-weight hydrogen-storage materials. Adv Mater 19 (2007) 2813-17.

[12] Broedersz CP, Gremaud R, Dam B, Griessen R, Lovvik OM. Highly destabilized Mg-Ti-Ni-H system investigated by density functional theory and Hydrogenography. Phys Rev B 2008;77:024204. 
[13] Koningsberger DC, Mojet BL, van Dorssen GE, Ramaker DE. XAFS spectroscopy; fundamental principles and data analysis. Top Catal 2000;10:143-55.

[14] Vaarkamp M, Linders JC, Koningsberger DC. A new method for the parameterization of phase shifts. Physica B 1995;208-209:159-60.

[15] Cook, Jr. JW, Sayers DE. Criteria for automatic x - ray absorption fine structure background removal. J Appl Phys 1981;52:5024.

[16] Newville M. IFEFFIT: interactive XAFS analysis and FEFF fitting. J Synchrotron Radiat 2001;8:322-24.

[17] Zabinsky SI, Rehr JJ, Ankudinnov A, Albers RC, Eller MJ. Multiple-scattering calculations of x-ray-absorption spectra. Phys Rev B 1995;25:2995-3009.

[18] Baldi A, Pálsson GK, Gonzalez-Silveira M, Schreuders H, Slaman M, Rector JH, et al. Mg/Ti multilayers: Structural and hydrogen absorption properties. Phys Rev B 2010;81:224203.

[19] Stern EA. Number of relevant independent points in X-ray absorption fine-structure spectra. Phys Rev B 1993;48:9825-27.

[20] Di Vece M, van der Eerden AMJ, Grandjean D, Westerwaal RJ, Lohstroh W, Nikitenko SG, et al. Structure of the $\mathrm{Mg}_{2} \mathrm{Ni}$ switchable mirror: An EXAFS investigation. Mater Chem Phys 2005;91:1-9.

[21] Schefer J, Fisher P, Halg W, Stucki F, Schlapbach L, Didisheim JJ, et al. New structure results for hydrides and deuterides of the hydrogen storage material $\mathrm{Mg}_{2} \mathrm{Ni}$. J Less-Common Met 1980;74:65-73. 
[22] Farangis B, Nachimuthu P, Richardson TJ, Slack JL, Perera RCC, Gullikson EM, et al. In situ x-ray-absorption spectroscopy study of hydrogen absorption by nickel-magnesium thin films. Phys Rev B 2003;67:085106.

[23] Noreus D, Werner PE, Alasafi K, Schmidt-Ihn E, Structural studies of TiNiH. Int J Hydrogen Energy 1985;10:547-50.

[24] Bucher H, Gutjahr MA, Beccu KD, Säufferer H. Intermetallic phases containing hydrogen-Ti-Ni-H System. Z Metallkd 1972;63:497-500.

[25] Zolliker P, Yvon K, Jorgensen JD, Rotella F, Structural studies of the hydrogen storage material magnesium nickel hydride $\left(\mathrm{Mg}_{2} \mathrm{NiH}_{4}\right)$. 2. Monoclinic low-temperature structure. Inorg Chem 1986;25:3590-93.

[26] Kreuzer HJ, March NH. Origin and information content of the compensation effect. Theor Chim Acta 1988;74:339-48.

[27] Olivieri A. Metstability and entropy. In : Greven A, Keller G, Warnecke G, editors. Entropy, Princeton: Princeton Univ. Press ;2003,p.233-250. 

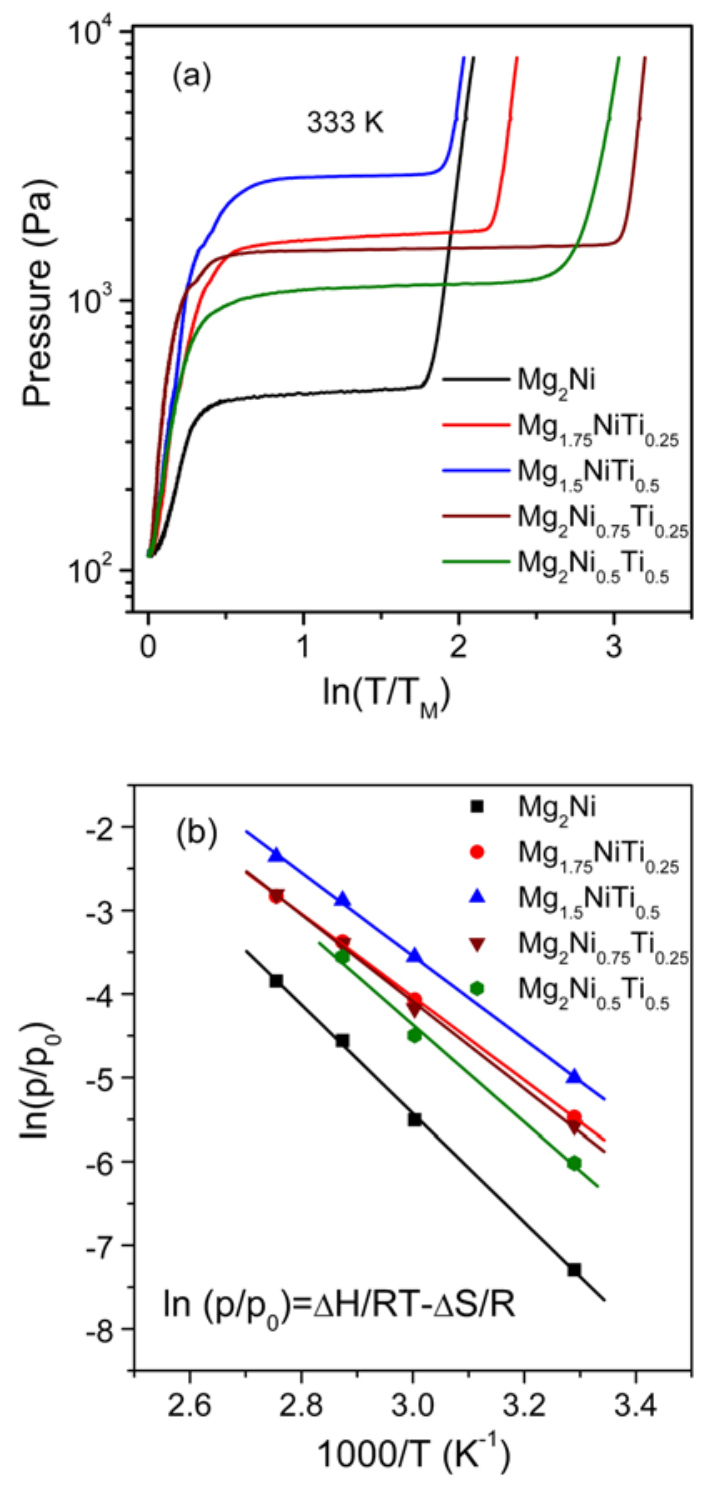

Figure 1 (a) Thee absorption pressure-optical-transmission-isotherms (PTIs) of $\mathrm{Mg}_{2-\mathrm{y}} \mathrm{NiTi}_{\mathrm{y}}(\mathrm{y}=0,0.25$ and 0.5$)$ and $\mathrm{Mg}_{2} \mathrm{Ni}_{1-\mathrm{x}} \mathrm{Ti}_{\mathrm{x}}(\mathrm{x}=0.25$ and 0.5$)$ measured at $\mathrm{T}=333$ K. (b) Construction of the Van 't Hoff plots in absorption for the corresponding samples. Different symbols stand for the experimental data. The full lines are the linear fits. 

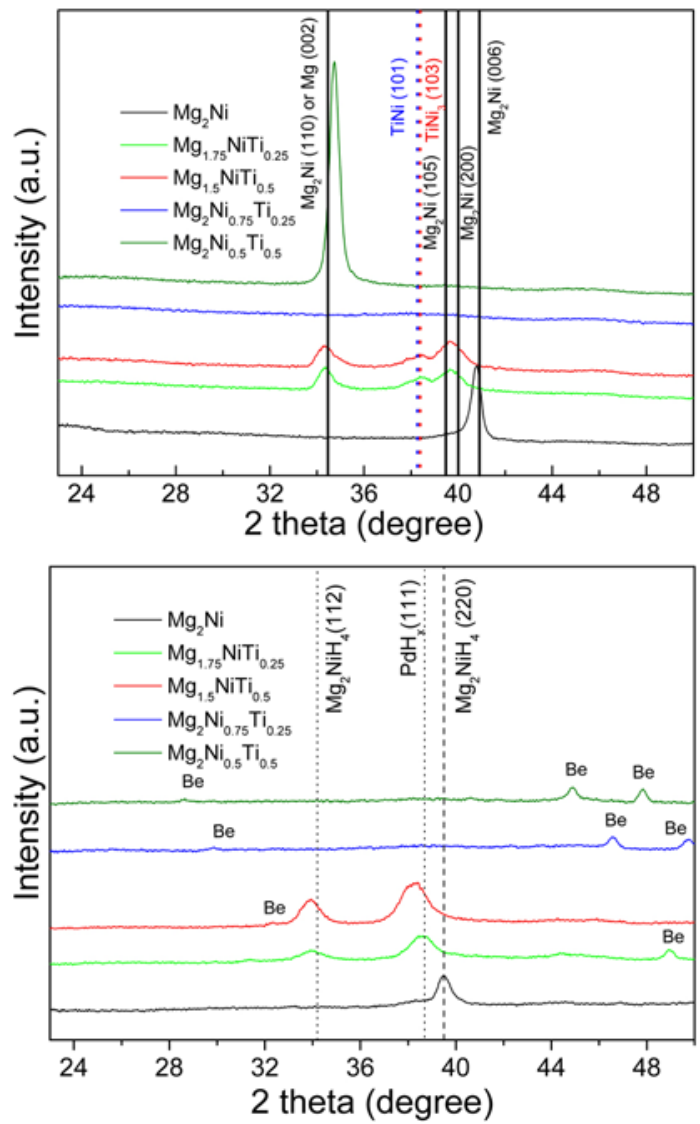

Figure 2 XRD patterns of the Mg-Ni-Ti samples. (a) as deposited state; (b) hydrogenated state. Be indicates reflections from the Beryllium dome; these peaks shift due to the fact that the relative position of the dome with respect to the sample is not the same for each measurement. 

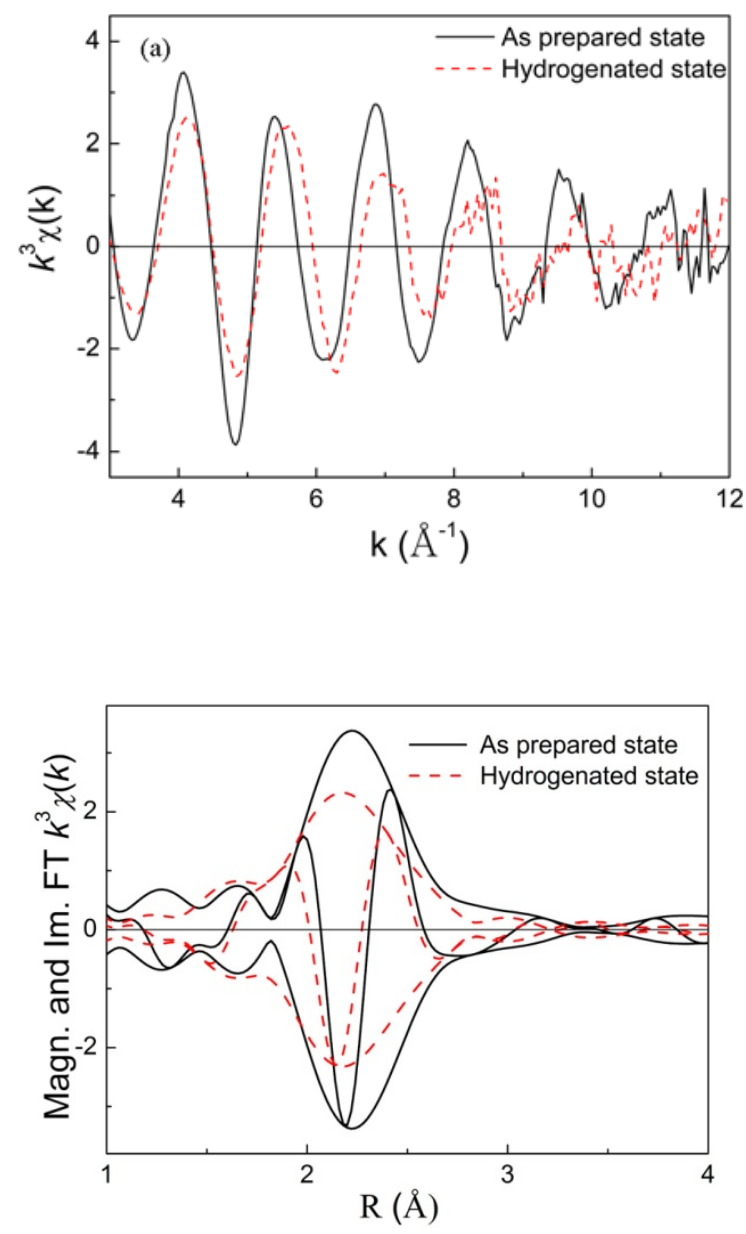

Fig. 3a: Background corrected EXAFS data for $\mathrm{Mg}_{2} \mathrm{Ni}$ films in the as-deposited (solid line) and in the hydrogenated state (dashed line) ( $\mathrm{k}^{3}$-weighted) b: Fourier transformed EXAFS data for $\mathrm{Mg}_{2} \mathrm{Ni}$ films in the as-deposited (solid line) and in the hydrogenated state (dashed line) $\left(\mathrm{k}^{3}\right.$-weighted, $\mathrm{k}$-range $=3-10$, uncorrected for phase shift). 


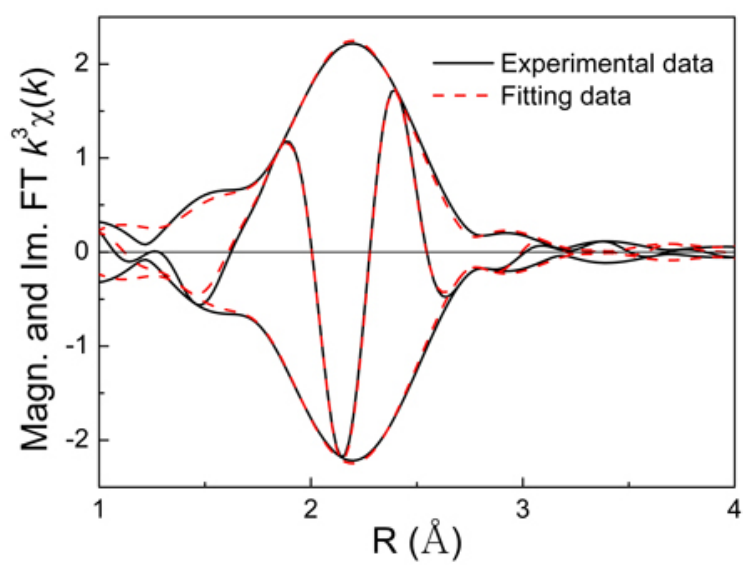

Fig. 4 Raw (solid line) and fitted EXAFS data (dashed line) of hydrogenated ( $\mathrm{k}^{3}$-weighted, $\Delta k=3-10 \AA^{-1}$ and $\Delta \mathrm{R}=1.5-3.0 \AA$ ).

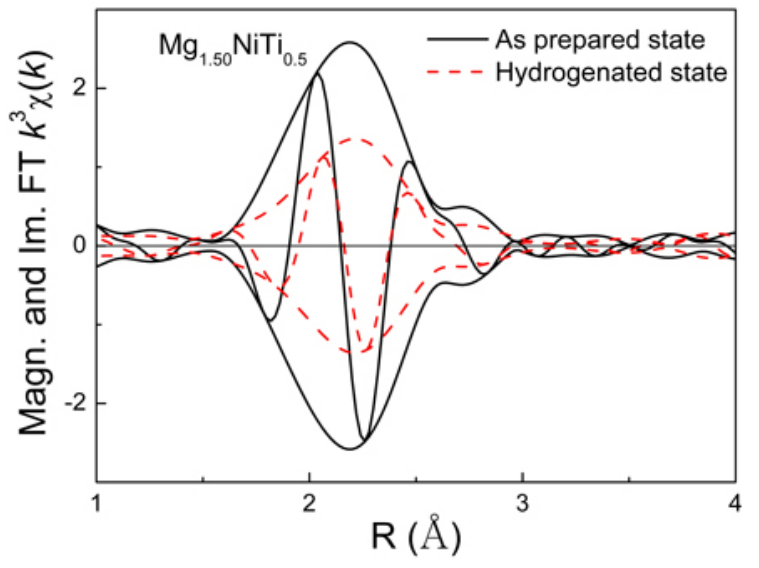

Fig. 5 Magnitude and imaginary part of the phase-uncorrected Fourier transformed $k^{3} \chi(k)$ for $\mathrm{Mg}_{1.5} \mathrm{NiTi}_{0.5}$ films in the as-deposited (solid line) and hydrogenated states (dashed line). 

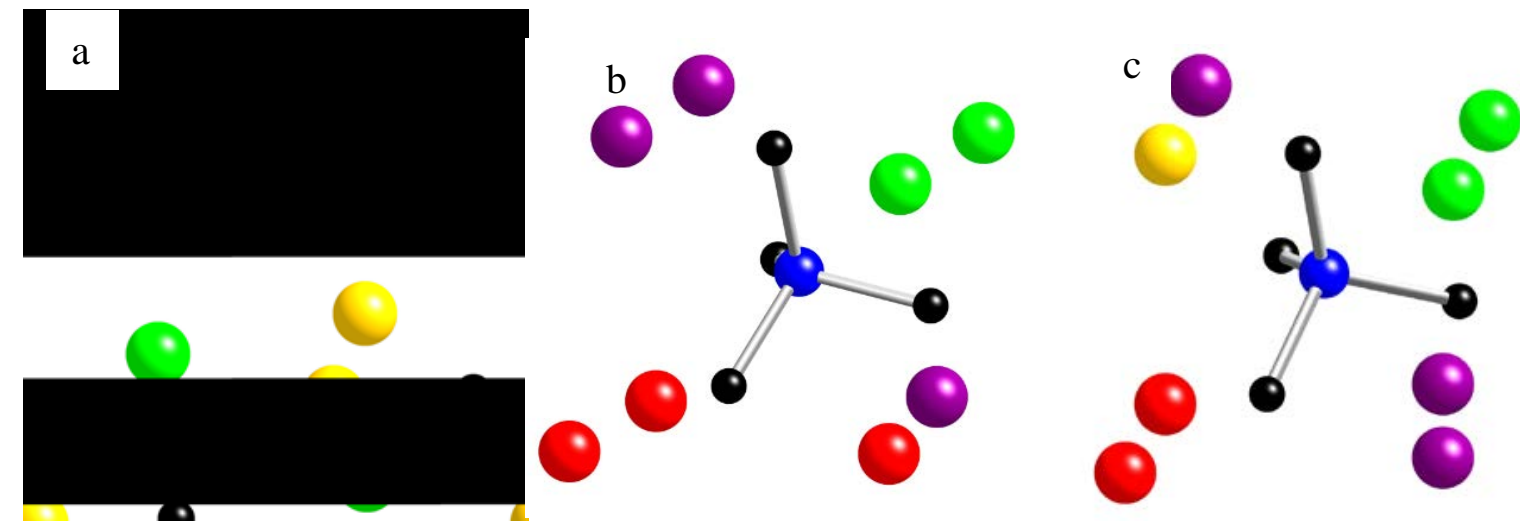

Figure 6 Schematics of (a) monoclinic structure, (b) model 1: Ti-doped $\mathrm{Mg}_{2} \mathrm{NiH}_{4}$-like monoclinic structure [Ti atoms located at $2 \mathrm{Mg} 3(4 \mathrm{e})$ and $1 \mathrm{Mg} 1(8 \mathrm{f})$ positions] in $\mathrm{Mg}_{1.5} \mathrm{NiTi}_{0.5} \mathrm{H}_{4}$ films and (c) model 2: Ti-doped $\mathrm{Mg}_{2} \mathrm{NiH}_{4}$-like monoclinic structure [Ti atoms located at $1 \mathrm{Mg} 3(4 \mathrm{e})$ and $2 \mathrm{Mg} 1(8 \mathrm{f})$ positions] in $\mathrm{Mg}_{1.5} \mathrm{NiTi}_{0.5} \mathrm{H}_{4}$ films in $\mathrm{Mg}_{1.5} \mathrm{NiTi}_{0.5} \mathrm{H}_{4}$ films. (red: Mg1; green: Mg2; yellow: Mg3: purple: Ti)

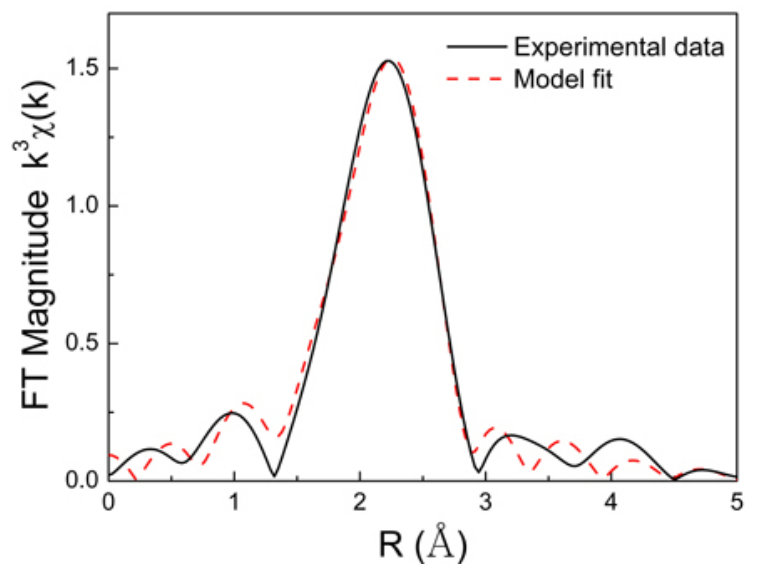

Fig. 7 Magnitude of the phase-uncorrected Fourier transformed $k^{3}$-weighted $\chi(\mathrm{k})$ nd IFEFFIT model 2 fitting for $\mathrm{Mg}_{1.5} \mathrm{NiTi}_{0.5}$ in the hydrogenated state. 


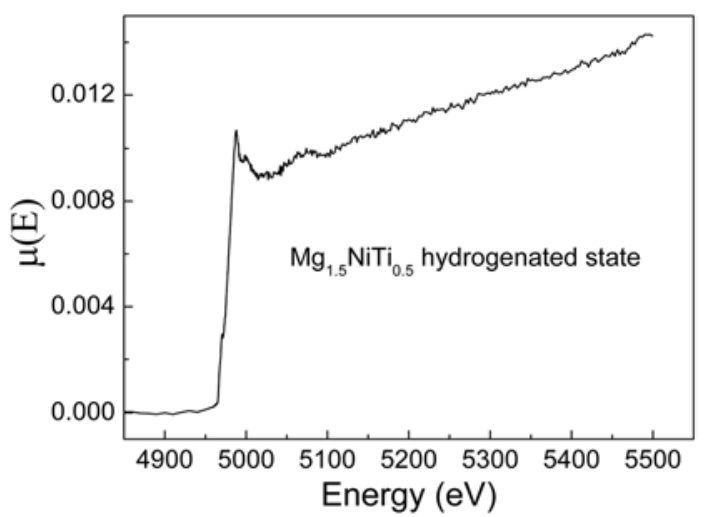

Figure 8. Absorption spectrum around the $\mathrm{Ti}$ K-edge for $\mathrm{Mg}_{1.5} \mathrm{NiTi}_{0.5}$ in the hydrogenated state. 
Table 1. Hydrogenation enthalpy and entropy of some compositions in Mg-Ni-Ti system measured in this study.

\begin{tabular}{lll}
\hline Compositions & Enthalpy of hydrogenation & Entropy \\
& $\Delta H\left(\mathrm{~kJ} / \mathrm{mol} \mathrm{H}_{2}\right)$ & $\Delta S\left(\mathrm{~J}^{-1} . \mathrm{mol}^{-1} \mathrm{H}_{2}\right)$ \\
\hline $\mathrm{Mg}_{2} \mathrm{Ni}$ & -54.0 & -116.8 \\
$\mathrm{Mg}_{1.75} \mathrm{NiTi}_{0.25}$ & -41.4 & -90.6 \\
$\mathrm{Mg}_{1.5} \mathrm{NiTi}_{0.5}$ & -41.5 & -95.0 \\
$\mathrm{Mg}_{2} \mathrm{Ni}_{0.75} \mathrm{Ti}_{0.25}$ & -43.3 & -95.9 \\
$\mathrm{Mg}_{2} \mathrm{Ni}_{0.5} \mathrm{Ti}_{0.5}$ & -48.4 & -108.7 \\
\hline
\end{tabular}


Table 2. Fitting parameters for samples $\mathrm{Mg}_{2-\mathrm{y}} \mathrm{NiTi}_{\mathrm{y}}(\mathrm{y}=0,0.25$ and $\mathrm{y}=0.5$ ) and $\mathrm{Mg}_{2} \mathrm{Ni}_{1-\mathrm{x}} \mathrm{Ti}_{\mathrm{x}}$ ( $\mathrm{x}=0.25$ and 0.50$)$ in the as-deposited and hydrogenated states: coordination number $N$, Debye-Waller factor $\Delta \sigma^{2}$, distance $R$ and inner potential correction $\Delta \mathrm{E}_{0}$.

\begin{tabular}{|c|c|c|c|c|c|c|c|}
\hline Samples and states & & Shell & $N$ & $\Delta \sigma^{2}$ & $R$ & $\Delta E_{0}$ & Phases \\
\hline \multirow{3}{*}{$\mathrm{Mg}_{2} \mathrm{Ni}$} & ac_prenared & $\mathrm{Ni}-\mathrm{Ni}$ & 213 & 787 & 254 & 930 & $\mathrm{Ma} \mathrm{Ni}$ \\
\hline & & Ni-Mg & 6.15 & 3.77 & 2.63 & 0.02 & \\
\hline & Hydrogenated & Ni-Mg & 5.59 & 8.71 & 2.64 & 0.14 & $\mathrm{Mg}_{2} \mathrm{NiH}_{4}$ \\
\hline \multirow[t]{4}{*}{$\mathrm{Mg}_{1.75} \mathrm{NiTi}_{0.25}$} & as-prepared & Ni-Mg & 5.62 & 16.0 & 2.72 & -2.85 & Ti-Ni intermetallics \\
\hline & & $\mathrm{Ni}-\mathrm{Ti}$ & 0.96 & 4.29 & 2.46 & 4.11 & $\mathrm{Mg}_{2} \mathrm{Ni}$ \\
\hline & Hydrogenated & $\mathrm{Ni}-\mathrm{Ti}$ & 1.36 & 26.91 & 2.65 & 3.14 & Ti-doped $\mathrm{Mg}_{2} \mathrm{NiH}_{4}$ \\
\hline & & Ni-Mg & 5.64 & 15.05 & 2.60 & 0.36 & \\
\hline \multirow[t]{4}{*}{$\mathrm{Mg}_{1.5} \mathrm{NiTi}_{0.5}$} & as-repared & $\mathrm{Ni}-\mathrm{Ti}$ & 3.95 & 10.24 & 2.55 & -2.40 & Ti-Ni intermetallics \\
\hline & & Ni-Mg & 4.70 & 7.43 & 2.64 & -3.56 & $\mathrm{Mg}_{2} \mathrm{Ni}$ \\
\hline & Hydrogenated & $\mathrm{Ni}-\mathrm{Ti}$ & 2.62 & 11.05 & 2.59 & -2.24 & Ti-doped $\mathrm{Mg}_{2} \mathrm{NiH}_{4}$ \\
\hline & & Ni-Mg & 4.38 & 8.04 & 2.694 & -5.85 & \\
\hline \multirow[t]{4}{*}{$\mathrm{Mg}_{2} \mathrm{Ni}_{0.75} \mathrm{Ti}_{0.25}$} & as-prepared & $\mathrm{Ni}-\mathrm{Ti}$ & 5.48 & 9.61 & 2.564 & -8.02 & Ti-Ni intermetallics \\
\hline & & Ni-Mg & 5.65 & 23.58 & 2.700 & -6.01 & $\mathrm{Mg}_{2} \mathrm{Ni}$ \\
\hline & Hydrogenated & $\mathrm{Ni}-\mathrm{Ti}$ & 0.86 & 7.36 & 2.741 & 3.17 & Ti-doped $\mathrm{Mg}_{2} \mathrm{NiH}_{4}$ \\
\hline & & Ni-Mg & 6.37 & 17.96 & 2.681 & -0.32 & \\
\hline \multirow[t]{4}{*}{$\mathrm{Mg}_{2} \mathrm{Ni}_{0.5} \mathrm{Ti}_{0.5}$} & as-prepared & $\mathrm{Ni}-\mathrm{Ti}$ & 4.72 & 10.80 & 2.516 & -3.32 & Ti-Ni intermetallics \\
\hline & & Ni-Mg & 7.23 & 14.92 & 2.580 & -5.37 & $\mathrm{Mg}_{2} \mathrm{Ni}$ \\
\hline & Hydrogenated & $\mathrm{Ni}-\mathrm{Ti}$ & 2.64 & 17.99 & 2.662 & 7.86 & Ti-doped $\mathrm{Mg}_{2} \mathrm{NiH}_{4}$ \\
\hline & & Ni-Mg & 4.36 & 8.46 & 2.706 & 3.00 & \\
\hline
\end{tabular}


Table 3 Comparison of Ni-NN distance and coordination numbers in the theoretical (DFT), experimental, model and IFEFFIT structure.

\begin{tabular}{l|lll}
\hline & Shell & $N$ & $R(\AA)$ \\
\hline Theory & $\mathrm{Ni}-\mathrm{Ti}$ & 2 & $2.61(\mathrm{Mg} 1)$ or $2.78(\mathrm{Mg} 3)$ \\
\multirow{5}{*}{ Experiment } & $\mathrm{Ni}-\mathrm{Mg}$ & 5 & 2.68 or 2.63 \\
& $\mathrm{Ni}-\mathrm{Ti}$ & 2.62 & 2.59 \\
Model 1 & $\mathrm{Ni}-\mathrm{Mg}$ & 4.38 & 2.69 \\
Model 2 & $\mathrm{Ni}-\mathrm{Ti}$ & 3 & 2.71 \\
& $\mathrm{Ni}-\mathrm{Mg}$ & 4 & 2.66 \\
IFEFFIT & $\mathrm{Ni}-\mathrm{Ti}$ & 3 & 2.61 \\
& $\mathrm{Ni}-\mathrm{Mg}$ & 4 & 2.72 \\
& $\mathrm{Ni}-\mathrm{Ti}$ & 3 & 2.54 \\
& $\mathrm{Ni}-\mathrm{Mg}$ & 4 & 2.70 \\
\hline
\end{tabular}

Table 4 Fitting parameters for samples $\mathrm{Mg}_{2-\mathrm{y}} \mathrm{NiTi}_{\mathrm{y}}(\mathrm{y}=0,0.25$ and 0.5 ) and $\mathrm{Mg}_{2} \mathrm{Ni}_{1-\mathrm{x}} \mathrm{Ti}_{\mathrm{x}}$ (x=0.25 and 0.50 ) in the as-deposited state: coordination number $N$, Debye-Waller factor $\Delta \sigma^{2}$, distance $R$ and inner potential correction $\Delta \mathrm{E}_{0}$.

\begin{tabular}{l|llllllll}
\hline \multicolumn{2}{l}{ Samples and states } & Shell & $N$ & $\begin{array}{l}\Delta \sigma^{2} \\
\left(10^{-3} \AA^{-2}\right)\end{array}$ & $\begin{array}{l}R \\
(\AA)\end{array}$ & $\begin{array}{l}\Delta E_{0} \\
(\mathrm{eV})\end{array}$ & Phases \\
\hline $\mathrm{Mg}_{1.75} \mathrm{NiTi}_{0.25}$ & As-prepared & $\mathrm{Ti}-\mathrm{Ni}$ & 3.0 & 2.09 & 2.47 & -9.71 & $\mathrm{TiNi}_{3}$ \\
& & $\mathrm{Ti}-\mathrm{Ti}$ & 3.2 & 7.95 & 2.55 & 8.26 & \\
$\mathrm{Mg}_{1.5} \mathrm{NiTi}_{0.5}$ & As-prepared & $\mathrm{Ti}-\mathrm{Ni}$ & 7.0 & 8.89 & 2.46 & -1.38 & $\mathrm{TiNi}$ \\
$\mathrm{Mg}_{2} \mathrm{Ni}_{0.75} \mathrm{Ti}_{0.25}$ & As-prepared & $\mathrm{Ti}-\mathrm{Ni}$ & 7.0 & 2.36 & 2.46 & -3.49 & $\mathrm{TiNi}$ \\
& & $\mathrm{Ti}-\mathrm{Ti}$ & 1.2 & 0.75 & 2.76 & 1.19 & \\
$\mathrm{Mg}_{2} \mathrm{Ni}_{0.5} \mathrm{Ti}_{0.5}$ & As-prepared & $\mathrm{Ti}-\mathrm{Ni}$ & 8.1 & 11.32 & 2.50 & -5.76 & $\mathrm{TiNi}$ \\
& & $\mathrm{Ti}-\mathrm{Ti}$ & 3.3 & 10.87 & 2.82 & 5.86 & \\
\hline
\end{tabular}

